\title{
Prevalence and characteristics of supernumerary teeth in a non-syndrome Turkish population: Associated pathologies and proposed treatment
}

\author{
Mevlut Celikoglu ${ }^{1}$, Hasan Kamak ${ }^{1}$, Hüsamettin Oktay ${ }^{2}$ \\ ${ }^{1}$ Research Assistant, Department of Orthodontics, Faculty of Dentistry, Ataturk University, Erzurum, Turkey \\ ${ }^{2}$ Professor, Department of Orthodontics, Faculty of Dentistry, Ataturk University, Erzurum, Turkey
}

Correspondence:

Department of Orthodontics

Faculty of Dentistry

University of Ataturk

Erzurum, 25240, Turkey

mevlutcelikoglu@hotmail.com

Received: 26/07/2009

Accepted: 23/12/2009

\author{
Celikoglu M, Kamak H, Oktay H. Prevalence and characteristics of su- \\ pernumerary teeth in a non-syndrome Turkish population: Associated \\ pathologies and proposed treatment. Med Oral Patol Oral Cir Bucal. 2010 \\ Jul 1;15 (4):e575-8 \\ http://www.medicinaoral.com/medoralfree01/v15i4/medoralv15i4p575.pdf \\ Article Number: $3051 \quad$ http://www.medicinaoral.com/ \\ (C) Medicina Oral S. L. C.I.F. B 96689336 - pISSN 1698-4447 - eISSN: 1698-6946 \\ eMail: medicina@medicinaoral.com \\ Indexed in: \\ -SCI EXPANDED \\ -JOURNAL CITATION REPORTS \\ -Index Medicus / MEDLINE / PubMed \\ -EMBASE, Excerpta Medica \\ -SCOPUS \\ -Indice Médico Español
}

\begin{abstract}
Objective: The objectives of the present study were to investigate the prevalence and characteristics of supernumerary teeth and evaluate the associated pathologies and treatment protocol in a Turkish patient population.

Study design: A retrospective study was performed using full-mouth periapical and panoramic radiographs of 3491 patients (2146 females and 1345 males) ranging in age from 12 to 25 . For each patient with supernumerary teeth we recorded the demographic variables (including age, sex), number, location, position, type, and morphology of supernumerary teeth, associated pathologies or complications, and whether any treatment has been carried out. The Pearson chi-squared test was used to determine potential differences in the distribution of supernumerary teeth when stratified by gender.

Results: Supernumerary teeth were detected in 42 subjects (1.2\%), of which 27 were males and 15 were females with a 1.8:1 male female ratio $(\mathrm{P}<.001)$. The most commonly found supernumerary teeth were mesiodens $(31.3 \%)$ followed by premolar $(25.0 \%)$, lateral $(22.9 \%)$, distomolar (14.5\%), paramolar $(4.2 \%)$, and canine (2.1\%). Of the 48 supernumerary teeth examined, $50.0 \%(\mathrm{n}=24)$ were conical, $81.3 \%(\mathrm{n}=39)$ were in a vertical position, and $20.8 \%$ $(\mathrm{n}=10)$ were erupted. Supernumerary teeth caused rotation or displacement of the adjacent teeth in 14 cases, and the impaction of the permanent teeth in 8 cases.

Conclusion: The prevalence of supernumerary teeth in our series was found to be $1.2 \%$, the most frequent type being mesiodens. Rotation or displacement of permanent teeth was the most frequent complication caused by supernumerary teeth.
\end{abstract}

Key words: Supernumerary teeth, hyperdontia, mesiodens. 


\section{Introduction}

Supernumerary teeth or hyperdontia are defined as the existence of an excessive number of teeth in relation to the normal dental formula (20 in the deciduous dentition and 32 in the permanent dentition) (1). The reported prevalence of this abnormality varies between $0.1 \%$ and $3.8 \%$ in the permanent dentition in comparison with $0.3 \%$ to $0.6 \%$ in the deciduous dentition (2). Supernumerary teeth are more frequent in males than in females $(1,3-5)$.

The exact etiology of supernumerary teeth is unknown, however, several theories have been postulated to explain their presence: The phylogenetic theory as a regression to the anthropoids whose dental had more teeth, the autonomic recessive inheritance or linked to the $\mathrm{x}$ chromosome, an abnormal reaction to a local traumatic episode, environmental factors, dichotomy of the tooth germ and the theory of hyperactivity of the dental lamina, are the most accepted (6).

The most frequent location is in the maxilla, the anterior medial region (mesiodens), where $80 \%$ of all supernumerary teeth are found. More rarely, they can be located in the superior distomolar zone, inferior premolar, superior premolar, inferior distomolar, superior canine zone, and inferior incisor (1). Clinically, supernumerary teeth are able to cause different local disorders, such as retention of the primary tooth, delayed eruption of the permanent tooth, ectopic erup-tions, tooth displacements, follicular cysts, and other alterations, requiring surgical or orthodontic intervention $(7,8)$.

The objective of the present study was to investigate the prevalence and characteristics of supernumerary teeth and evaluate the associated pathologies and treatment protocol in a Turkish patient population; thus, being the first series of supernumerary teeth in our population described in the English literature.

\section{Patients and Methods}

A retrospective study was performed using full-mouth periapical and panoramic radiographs of 3491 patients (2146 females and 1345 males) ranging in age from 12 to 25 subjected to Faculty of Dentistry at the University of Ataturk (Erzurum, Turkey) between 1999 and 2008. Selection criteria of the samples included the patients that were not diagnosed with any syndrome or illness involved odontogenesis and dental eruption. For each patient with supernumerary teeth we recorded the demographic variables (including age, sex), number, location (maxilla or mandible), position, type, and morphology of supernumerary teeth, associated pathologies or complications (displacement, impossibility of eruption, resorptions of adjacent tooth, and presence of follicular cysts), and whether any treatment has been carried out. All radiographs were reviewed and discussed by the panel in a negatoscope an a7x lens was used. Interexaminer discrepancies were solved by consensus and agreement. The Pearson chi-squared test was used to determine potential differences in the distribution of supernumerary teeth when stratified by gender. A $p$ value of $<0.05$ was considered statistically significant.

\section{Results}

During the above mentioned time 3491 Turkish subjects (2146 females, 1345 males) were reviewed. Of them, supernumerary teeth were detected in 42 subjects $(1.2 \%)$, of which 27 were males and 15 were females with a 1.8:1 male female ratio $(\mathrm{P}<.001)$ (Table 1).

Table 2 shows the characteristics of supernumerary teeth. In $75.0 \%(n=36)$ of cases, one supernumerary tooth was observed, in $25.0 \%(\mathrm{n}=6)$ two supernumerary teeth were observed. However, cases with three or more supernumerary teeth were not observed. A total of 48 supernumerary teeth were observed, of which $68.8 \%(\mathrm{n}=33)$ were located in the maxillary arch, while $31.2 \%(n=15)$ were found in the mandible. The most commonly found supernumerary teeth were mesiodens (31.3\%) followed by premolar $(25.0 \%)$, lateral $(22.9 \%)$, distomolar (14.5\%), paramolar (4.2\%), and canine (2.1\%). Regarding their status within the arch, only $20.8 \%$ $(n=10)$ had erupted, and surprisingly all of them were supernumerary lateral teeth. Of the 48 supernumerary teeth examined, $50.0 \%(\mathrm{n}=24)$ were conical, and $81.3 \%$ $(n=39)$ were in a vertical position. Supernumerary teeth caused rotation or displacement of the adjacent teeth in 14 cases, and the impaction of the permanent teeth in 8 cases. In one case, impacted maxillary central incisor erupted spontaneously in 8 months after the extraction of erupted mesiodens. In seven cases, orthodontic forces were used for eruption of impacted permanent teeth. No cysts, enlargement in the follicular epithelium or root resorption were found. No other dental anomalies associated with supernumerary teeth were detected.

Table 1. Distribution of the supernumerary teeth according to the gender.

\begin{tabular}{|c|c|c|c|c|c|c|}
\hline Gender & $\mathbf{n}$ & Supernumerary teeth & Frequency (\%) & $\mathbf{x}^{\mathbf{2}}$ & P value & Totally (\%) \\
\hline Female & 2146 & 15 & 0.7 & & & \\
\cline { 1 - 4 } Male & 1345 & 27 & 2.0 & 11.59 & 0.0007 & $42(1.2)$ \\
\hline
\end{tabular}


Table 2. Characteristics of the supernumerary teeth.

\begin{tabular}{|c|c|c|c|}
\hline \multicolumn{2}{|c|}{ Supernumerary tooth characteristics } & Number & $\%$ \\
\hline \multicolumn{2}{|c|}{ Total number } & 48 & 100 \\
\hline \multirow{6}{*}{ Type } & Mesiodens & 15 & 31.3 \\
\hline & Lateral & 11 & 22.9 \\
\hline & Canine & 1 & 2.1 \\
\hline & Premolar & 12 & 25.0 \\
\hline & Paramolar & 2 & 4.2 \\
\hline & Distomolar & 7 & 14.5 \\
\hline \multirow{2}{*}{ Number } & Single & 36 & 75.0 \\
\hline & Double & 6 & 25.0 \\
\hline \multirow[b]{2}{*}{ Location } & Maxilla & 33 & 68.8 \\
\hline & Mandible & 15 & 31.2 \\
\hline \multirow{2}{*}{ Status } & Impacted & 38 & 79.2 \\
\hline & Erupted & 10 & 20.8 \\
\hline \multirow{4}{*}{ Position } & Vertical & 39 & 81.3 \\
\hline & Horizontal & 3 & 6.2 \\
\hline & Inverted & 2 & 4.2 \\
\hline & Mesioangular & 4 & 8.3 \\
\hline \multirow{4}{*}{ Morphology } & Eumorphic & 15 & 31.2 \\
\hline & Conical & 24 & 50.0 \\
\hline & Tubercular & 8 & 16.7 \\
\hline & Mixed & 1 & 2.1 \\
\hline \multirow{3}{*}{ Complications } & impaction & 8 & 16.7 \\
\hline & crowding & 14 & 29.2 \\
\hline & asymptomatic & 26 & 54.1 \\
\hline \multirow[b]{2}{*}{ Treatment } & ext & 43 & 89.6 \\
\hline & observation & 5 & 10.4 \\
\hline
\end{tabular}

The supernumerary teeth were extracted in most of the patients, especially in which complication was detected. However, five patients chose to keep supernumerary teeth and undergo periodical revisions, since no complications were observed due to the supernumerary teeth.

\section{Discussion}

Supernumerary teeth are infrequent developmental alterations that may manifest in any zone of the dental arches and involve any tooth. They may be associated with a syndrome or they can be found in non-syndromic patients (1) Current data in the literature show that supernumerary teeth are observed in $0.1 \%$ to $3.8 \%$ of the general population but this prevalence can be as high as $28 \%$ in patients with cleft and lip palate $(2,9,10)$. In our study, the prevalence of supernumerary teeth was found to be $1.2 \%$ and more frequent in males than in females with a male female ratio of 1.8:1 $(\mathrm{P}<.001)$. It was in agreement with the data reported that males are affected approximately twice as frequently as females in the permanent dentition $(1,4,11,12)$.

It is well established that supernumerary teeth are more frequently single tooth, while multiple supernumerary teeth appear frequently as two teeth. $(13,14)$ In agreement with the literature, $75 \%(\mathrm{n}=36)$ of the supernumerary teeth were found to be single and $25 \%(n=6)$ were as two teeth.

Regarding the location of observed supernumerary teeth in the present study, $68.8 \%(n=33)$ of the supernumerary teeth were found to be in the maxillary arch. This value was very close to the data reported by Salcido-Garcia et al. (5) who found that $66 \%$ of the supernumerary teeth 
to be in maxillary arch. Additionally, Gomes et al. (8) reported that $91.3 \%$ of the cases located in maxilla.

The most commonly found supernumerary tooth has been reported to be mesiodens $(4,5,15)$, some authors $(15,16)$ consider that mesiodens are followed by distomolars, but others $(1,5)$ found that mesiodens are followed by lateral incisors and premolars. Yusof (17), made a review of the literature and found the premolars were the most frequent supernumerary teeth followed by molars and mesiodens. The results of the present study in Turkish population showed that the most commonly found supernumerary teeth were mesiodens $(31.3 \%)$ followed by premolars $(25.0 \%)$, lateral incisors $(22.9 \%)$, distomolars $(14.5 \%)$, paramolars $(4.2 \%)$, and canines $(2.1 \%)$.

Supernumerary teeth can be either eumorphic or supplemental and dysmorphic: conical, tubercular, mixed (11). Conical shape was found to be the most common observed morphology in the present study and this value was in agreement with the literature $(8,13,18)$. When assessing eruption status, we found that $20.8 \%(n=10)$ of the supernumerary teeth were erupted. Similar frequencies of erupted supernumerary teeth have been reported by other authors $(8,13,18)$. Liu (18) and Gomes et al. (8) showed that eumorphic teeth had a higher frequency of erupting. We also observed that $70 \%(n=7)$ of the supernumerary teeth erupted were with an eumorphic morphology. Remaining 30\% $(n=3)$ were conical shape. All erupted supernumerary teeth were eumorphic and conical. In agreement with the data reported by many authors $(8,13)$, our study showed that the most commonly found position for supernumerary teeth was vertical position and all erupted supernumerary teeth were in a vertical position.

Interestingly, in 2007, Gomes et al. (8) found that $88.5 \%$ of the patients with supernumerary teeth had clinical complications. Clinical complications caused by supernumerary teeth, in the present study, were observed in $45.9 \%(n=22)$ of the subjects and displacement was the most frequently found complication. No cysts, enlargement in the follicular epithelium or root resorption were found. No other dental anomalies associated with supernumerary teeth were detected. In agreement with our finding, other authors $(11,13,19)$ showed that displacement was a clinical complication frequently observed. In eight cases, the eruption of permanent teeth was obstructed by supernumerary teeth. There is a consensus in the literature that surgical removal of supernumerary teeth is indicated whenever clinical or radiographic complications are found. Therefore, supernumerary teeth caused impaction of permanent teeth were surgically removed instantaneously. In one case, impacted maxillary central incisor erupted spontaneously in 8 months after the extraction of erupted mesiodens. In seven cases, orthodontic forces were used for eruption of impacted permanent teeth. In the treatment protocol, 5 out of 48 supernumerary teeth were observed periodically and remaining 43 were removed surgically or not.

\section{References}

1. Leco Berrocal MI, Martín Morales JF, Martínez González JM. An observational study of the frequency of supernumerary teeth in a population of 2000 patients. Med Oral Patol Oral Cir Bucal. 2007; 12:E134-8

2. Díaz A, Orozco J, Fonseca M. Multiple hyperodontia: report of a case with 17 supernumerary teeth with non syndromic association. Med Oral Patol Oral Cir Bucal. 2009;14:E229-31.

3. Alaejos C, Contreras MA, Buenechea R, Berini L, Gay C. Mesiodens: a retrospective study of 44 patients. Med Oral. 2000;5:81-8.

4. Ferrés-Padró E, Prats-Armengol J, Ferrés-Amat E. A descriptive study of 113 unerupted supernumerary teeth in 79 pediatric patients in Barcelona. Med Oral Patol Oral Cir Bucal. 2009;14:E146-52.

5. Salcido-García JF, Ledesma-Montes C, Hernández-Flores F, Pérez D, Garcés-Ortíz M. Frequency of supernumerary teeth in Mexican population. Med Oral Patol Oral Cir Bucal. 2004;9:407-9; 403-6.

6. Rao PV, Chidzonga MM. Supernumerary teeth: literature review. Cent Afr J Med. 2001;47:22-6.

7. Zilberman Y, Malron M, Shteyer A. Assessment of 100 children in Jerusalem with supernumerary teeth in the premaxillary region. ASDC J Dent Child. 1992;59:44-7.

8. De Oliveira Gomes C, Drummond SN, Jham BC, Abdo EN, Mesquita RA. A survey of 460 supernumerary teeth in Brazilian children and adolescents. Int J Paediatr Dent. 2008;18:98-106.

9. Nazif MM, Ruffalo RC, Zullo T. Impacted supernumerary teeth: a survey of 50 cases. J Am Dent Assoc. 1983;106:201-4.

10. Sacal C, Echeverri EA, Keene H. Retrospective survey of dental anomalies and pathology detected on maxillary occlusal radiographs in children between 3 and 5 years of age. Pediatr Dent. 2001;23:34750.

11. Garvey MT, Barry HJ, Blake M. Supernumerary teeth--an overview of classification, diagnosis and management. J Can Dent Assoc. 1999;65:612-6.

12. Kinirons MJ. Unerupted premaxillary supernumerary teeth. A study of their occurrence in males and females. Br Dent J. 1982;153:110.

13. Rajab LD, Hamdan MA. Supernumerary teeth: review of the literature and a survey of 152 cases. Int J Paediatr Dent. 2002;12:24454.

14. Tay F, Pang A, Yuen S. Unerupted maxillary anterior supernumerary teeth: report of 204 cases. ASDC J Dent Child. 1984;51:28994.

15. Fernández Montenegro P, Valmaseda Castellón E, Berini Aytés L, Gay Escoda C. Retrospective study of 145 supernumerary teeth. Med Oral Patol Oral Cir Bucal. 2006;11:E339-44.

16. Menardía-Pejuan V, Berini-Aytés L, Gay-Escoda C. Supernumerary molars. A review of 53 cases. Bull Group Int Rech Sci Stomatol Odontol. 2000;42:101-5.

17. Yusof WZ. Non-syndrome multiple supernumerary teeth: literature review. J Can Dent Assoc. 1990;56:147-9.

18. Liu JF. Characteristics of premaxillary supernumerary teeth: a survey of 112 cases. ASDC J Dent Child. 1995;62:262-5.

19. Asaumi JI, Shibata Y, Yanagi Y, Hisatomi M, Matsuzaki H, Konouchi H, et al. Radiographic examination of mesiodens and their associated complications. Dentomaxillofac Radiol. 2004;33:125-7. 